\title{
Exploring Reviews and Review Sequences on E-Commerce Platform: A study of Helpful Reviews on Amazon.in
}

\author{
$\underline{\text { Author Details }}$ \\ Kapil Kaushik \\ Indian Institute of Management \\ Prabandh Shikhar, Rau-Pithampur Road \\ Indore, Madhya Pradesh 453556, India \\ Email: f13kapilk@iimidr.ac.in \\ Rajhans Mishra \\ Indian Institute of Management \\ Prabandh Shikhar, Rau-Pithampur Road \\ Indore, Madhya Pradesh 453556, India \\ Email: rajhansm@iimidr.ac.in \\ Nripendra P. Rana* \\ School of Management \\ Swansea University Bay Campus \\ Fabian Way, Swansea, SA1 8EN, UK \\ Email: nrananp@gmail.com \\ Phone: (+44)1792-295179 \\ Yogesh K. Dwivedi \\ School of Management \\ Swansea University Bay Campus \\ Fabian Way, Swansea, SA1 8EN, UK \\ Email: ykdwivedi@gmail.com \\ *Corresponding Author
}

\begin{abstract}
Prominent e-commerce platforms allow users to write reviews for the available products. User reviews play an important role in creating the perception of the product and impact the sales. Online reviews can be considered as an important source of e-word of mouth (e-WOM) on ecommerce platforms. Various dimensions of e-WOM on product sales have been examined for different products. Broadly, studies have explored the effect of summary statistics of reviews on product sales using data from various e-commerce platforms. Few studies have utilized other review characteristics as length, valence, and content of the reviews. The sequence of reviews has been hardly explored in the literature. This study investigates the impact of sequence of helpful reviews along with other review characteristics as ratings (summary statistics), volume, informativeness, and valence of reviews on product sales. Hence, a holistic approach has been
\end{abstract}


used to explore the role of summary statistics, volume, content and sequence of reviews on product sales with special emphasis on sequence of reviews. Relevant theories such as message persuasion, cognitive overload and belief adjustment model have also been explored during the construction of the model for review data. The proposed model has been validated using the helpful reviews available on Amazon.in website for various products.

Keywords: Sequence of reviews, information overload, message persuasion, cognitive load, helpful reviews, Amazon

\section{Introduction}

With the advent of Web 2.0, multiple platforms have come up on the Web domain, which allows generation of data from users' side as well. Social networking websites, e-commerce websites, intermediary content aggregators (such as TripAdvisor) are some of the popular platforms where a massive amount of data that gets generated on daily basis. Social networking websites get data about the various activities and discussions of users while e-commerce platforms receive product review and rating data (Plotkina and Munzel, 2016; Saumya et al., 2018; Singh et al., 2016). All these platforms are sitting on a heap of data and looking for mining the nuggets from the usergenerated data for efficient decision-making process for their platforms (Weisstein et al., 2017).

Social networking websites aim to effectively personalize the sponsored content projected for the customers while e-commerce websites try to make sense out of review data to optimize their platforms.

This paper focuses on the review data generated on e-commerce website and how it can impact the sales of the product for the e-commerce platforms. The relationship between various dimensions of product reviews and its impact on product sales has been studied in the literature as well. Some of the dimensions that have been explored are average ratings, variance of ratings, valance, and volume of reviews. Different models have been proposed in the existing literature to identify the impact of review data on the product sales (Chintagunta, 2010; Hu, Liu, \& Zhang, 2008; Liu, 2006). Taking evidence from review length data, Chevalier \& Mayzlin (2006) suggested that customers also read reviews rather just relying on summary statistics of reviews. It suggests the impact of other characteristics of reviews (i.e. text characteristics) on the decisionmaking process for product purchase.

Reviews projected by the e-commerce platforms on the product page can be thought as a set of recommendations to the users that are looking for information (Dixit et al., 2017). 
Considering the amount of information that is available about a product, it will be difficult for any user to go through all the reviews and make sense of it. Hence, e-commerce platforms present the most useful or popular reviews on the product page to ease the decision-making process of the user. The reviews projected by e-commerce platforms may help the users for taking the decision regarding the product as well as optimize the sales through the platform. These reviews can also be thought as a set of messages related to the product. This set of messages consists of mixed messages (positive and negative) about the product.

Theories present in literature explain the effect of various message characteristics on the final judgment of message receiver. Message persuasion theory (Petty \& Cacioppo, 2012) recommends that source credibility/message authenticity influences the final judgment of user about an entity that is being discussed in messages. Belief adjustment model (Hogarth \& Einhorn, 1992) suggests that in a case of mixed messages about an entity, order of messages influences the final judgment of message receiver about the entity. It suggests that order of reviews, content richness, and review authenticity may influence the purchase intention and final judgment of user about the product. Cognitive overload theory by Jones, Ravid, \& Rafaeli (2010) suggests that information content of reviews increases the complexity of message. Though the focus of existing literature was on the content of the review, the sequential part of the review data has been ignored.

According to belief adjustment model (Hogarth \& Einhorn, 1992), sequence of reviews may also play an important role in the decision-making process of the user. The role of the sequence of reviews on e-commerce platforms has not been explored in depth. This work investigates the impact of various dimensions of review data (as ratings, valence, information richness, source credibility) along with review sequences on product sales. Study of sequence of reviews will add more significant value to the existing body of literature.

The objective of this study is to explore the effect of various characteristics of helpful reviews on product sales with special focus on review sequence with respect to valence and informativeness using data from e-commerce platform amazon.in. Considering the various review characteristics and sequence information, we have built an exhaustive model to study the impact of these review features on product sales. We have downloaded product information and reviews from the Amazon website (Amazon.in) to empirically validate the model.

The rest of the paper is organized as follows: literature review and relevant theories have been discussed in Section 2. The proposed framework and hypothesis has been discussed in Section 3, 
followed by research methodology in Section 4. Section 5 reports the results and discussion while the conclusion and future work are given in Section 6.

\section{Literature Review}

This section explains the previous work and relevant theories related to this context. Accordingly, this section has been divided into two subsections. The first section talks about the previous studies that have analysed the effect of online reviews on product sales. In the second section, we have briefly explained relevant theories, which might be applicable in this context and would be used as the basic premise of our theoretical model.

\subsection{Related Work and Research Gap}

Amazon e-commerce has been widely used as a data source in various studies for the purpose of analysis (e.g., Forman \& Ghose, 2008; Zhu \& Zhang, 2010). Amazon.in publishes sale rank of each product in its category. SaleRank (see Figure 1) for each product is published every week. SaleRank is determined by the relative sale of that product as compared to other products in past 24 hours. The negative logarithm of sale rank is widely used as proxy for product sale (Cui, Lui, \& Guo, 2012). Using this platform, previous studies have examined the effect of summary statistics of all the reviews of a product on its sales.

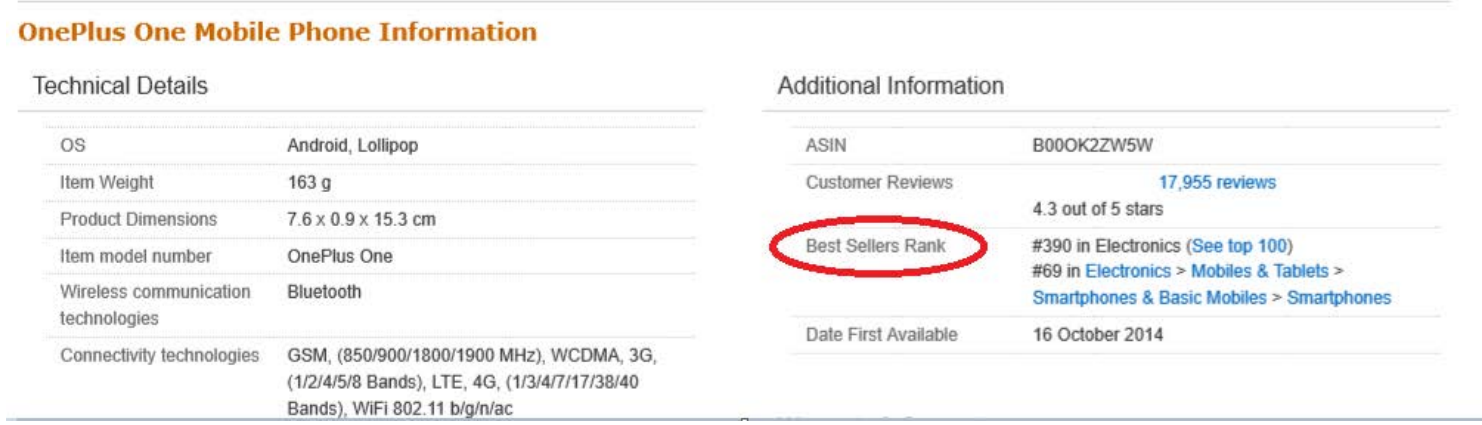

Figure 1. SaleRank on Amazon.in

Relationship between various dimensions of review statistics such as ratings, sentiments, volume and variance with product sales has been explored in past studies. Initial studies have largely focused on volume and ratings of reviews on product sales. Clemons, Gao, \& Hitt (2006) found that variance of ratings and positive reviews influences the product sales growth in the beer industry. Chevalier \& Mayzlin (2006) explored the effect of review ratings and review length on product sales at amazon.com platform. Though, review ratings were found to be having postive effect on product sales, but effect of review length was insignificant. Duan, Gu, \& Whinston 
(2008a) also found that volume and valence for online word of mouth positively impacts the box office performance of movies. Similarly, Ghose \& Ipeirotis (2010) also explored the impact of reviews on sales. Chintagunta (2010) has examined the effect of variance of ratings. Valence (positive or negative fraction of reviews) is explored by (Liu, 2006). The positive effect of volume, ratings and valence of online reviews on product sales has been widely explored and supported by studies (Dellarocas, Awad, \& Zhang, 2004; Duan, Gu, \& Whinston, 2008b; Liu, 2006). Along with valence, variance in the valence is also found to be having an impact on product sales variation in valence (Hu, Koh, \& Reddy, 2014).

Studies discussed in the previous paragraph primarily focused on volume and ratings of reviews and other aspects of reviews were not considered in exploring product sales at e-commerce platform. Other than summary statistics of reviews (valence and volume), some studies have aimed to understand the impact of qualitative aspect of online reviews on product sales. For example, $\mathrm{Hu}$, Liu, \& Zhang (2008) found that along with quantitative aspect i.e. rating of reviews, customer's decision is influenced by the qualitative aspect of reviews such as reviewer quality, review quality etc. (Roy et al., 2018). Similarly, the role of review quality and reviewer's characteristics is analysed by Lee \& Shin (2014). Some of the studies also explored that effect of online reviews on product sales varies with contextual factors such as product category (Cui et al., 2012), product popularity (Zhu \& Zhang, 2010) and consumer characteristics (Zhu \& Zhang, 2010).

As far as above mentioned works are concerned, all of them focused on summary statistics of online reviews, review quality, product category, and consumer characteristics. There exist scant studies that proposed to investigate the reviews order/sequence and informativeness on product sales at e-commerce platforms. For example, Purnawirawan, Pelsmacker, \& Dens (2012) investigated the effect of the balance of reviews (ratio of positive to negative reviews) and review sequence on the usefulness of a set of online reviews. Their study used consumer survey approach for investigating the role of balance and review sequence and found that not only balance but reviews sequence has a significant effect on the usefulness of reviews. Further, Purnawirawan, Dens, \& Pelsmacker (2012) also examined the effect of review balance and review sequence on recall and impression of the consumer about reviews. It was found that consumer first relies on review balance. In a case of neutral balance, consumer relies on review sequence for impression formation. Exploring the role of review balance on purchase intention in the experimental setup, Purnawirawan (2014) found that positive balance generates favorable response among consumers. 
Thus it is obvious that review balance and review sequence are gaining importance in e-WOM studies. However, these studies have relied upon consumer surveys and experimental studies to explore the role of review sequence and review balance in the online purchase. There is a lack of studies that have explored the role of review sequence in real-time settings i.e. using data from some e-commerce platforms. Hence, this study proposes to study the impact of balance and sequence of popular reviews on product sales using real time data from e-commerce platform of amazon.in. Hence, this study propose to study the impact of sequence of reviews along with the other review charatcterisitcs of helpful (popular reviews) on amazon.in platform.

\subsection{Relevant Theories}

E-commerce platform like Amazon allows users to write reviews for the products, which provide useful information for other users. A single product may have various reviews from different users creating a set of messages for the product. Previous studies in literature that have examined the impact of a set of messages on consumer's judgment about product and factors that affect consumer's processing of messages (Buda \& Zhang, 2000). There are theories that explain the effect of message characteristics on consumer's final judgment about the product. These message characteristics include information volume and persuasiveness of messages. This work utilizes perspectives from cognitive overload theory, message persuasion theory and belief adjustment model to conceptualize effect of helpful review characteristics on product sales.

Important aspect that may affect the decision-making process of the consumer is the amount of content/volume of information available in online reviews. Online reviews should contain enough information to make the consumer cognizant of product's features, performance, pros \& cons etc. However, it has also been observed that when the consumer is exposed to too much information, it causes cognitive overload/information overload (Kirsh, 2000) for the consumer. Cognitive overload theory (Jones, Ravid, \& Rafaeli, 2004) explains the information processing abilities of users. In online communication, overload may be caused when the user is not able to determine the significance of incoming messages (Hiltz \& Turoff, 1985 as cited in Li, Kankanhalli, \& Kim, 2016). Thus, when reviews contain excessive and repetitive information, user may feel overloaded (Hiltz \& Turoff, 1985). Above discussion suggests that more information makes the consumer overloaded with information, and thus hampers the decision-making ability of the user. 
Another important aspect that influences the decision making of customers is persuasiveness of reviews. The persuasiveness of product related messages creates a favourable perception about the product in consumer's mind. Thus, it may be argued that persuasiveness of online reviews would affect the likelihood of a product being purchased. Thus, persuasiveness of reviews would play a significant role in affecting the product Sales. Factors that make a message more persuasive are explained by message persuasion theory (Petty \& Cacioppo, 2012). This theory emphasizes that source credibility of a message makes it more persuasive. Messages originating from a credible source are more persuasive to customers than non-credible sources. In case of multiple messages, message order also influences the persuasiveness along source credibility. Belief adjustment model (Hogarth \& Einhorn, 1992) suggests that message order affects the decision-making process and final judgment of message recipient. Effect of message order on consumer's final judgment about the product is also found by Haugtvedt \& Wegener (1994). A summary of the relevant theories along with the related variable has been presented in Table 1.

Table 1. Brief summary of theories used in this study

\begin{tabular}{|l|l|l|}
\hline Theory/Model & Brief Description & Variables in our study \\
\hline $\begin{array}{l}\text { Cognitive Overload } \\
\text { Theory }\end{array}$ & $\begin{array}{l}\text { Lengthy messages contribute to complexity of message, } \\
\text { and more length of message increases cognitive } \\
\text { overload of user (Jones, Ravid, \& Rafaeli, 2004) }\end{array}$ & $\begin{array}{l}\text { Number of helpful review } \\
\text { and average } \\
\text { Informativeness of helpful } \\
\text { reviews }\end{array}$ \\
\hline $\begin{array}{l}\text { Message Persuasion } \\
\text { Theory }\end{array}$ & $\begin{array}{l}\text { Source credibility makes the message more persuasive } \\
\text { (Petty \& Cacioppo, 2012) }\end{array}$ & $\begin{array}{l}\text { Percentage of verified } \\
\text { purchase reviews }\end{array}$ \\
\hline $\begin{array}{l}\text { Belief Adjustment } \\
\text { Model }\end{array}$ & $\begin{array}{l}\text { Message order influences the final judgment of } \\
\text { consumer(Hogarth \& Einhorn, 1992) }\end{array}$ & $\begin{array}{l}\text { Sequence of negative } \\
\text { helpful reviews }\end{array}$ \\
\hline
\end{tabular}

\section{Proposed Framework}

In this section, we will explain the theoretical model that has been built on the basis of the existing literature and relevant theories. We have proposed the hypotheses for testing the effect of helpful reviews on product sales. Different aspects of user generated content (product reviews) given on product page, and their effect on product sales is theorized in following three sub-sections. In the first subsection, we have hypothesized testing the effect of the Informativeness of helpful reviews. The effect of message persuasiveness of helpful reviews is theorized in the second section. Finally, 
hypotheses are proposed for the effect of valence and sequence of helpful reviews in the third section. The conceptual diagram is shown in Figure 2.

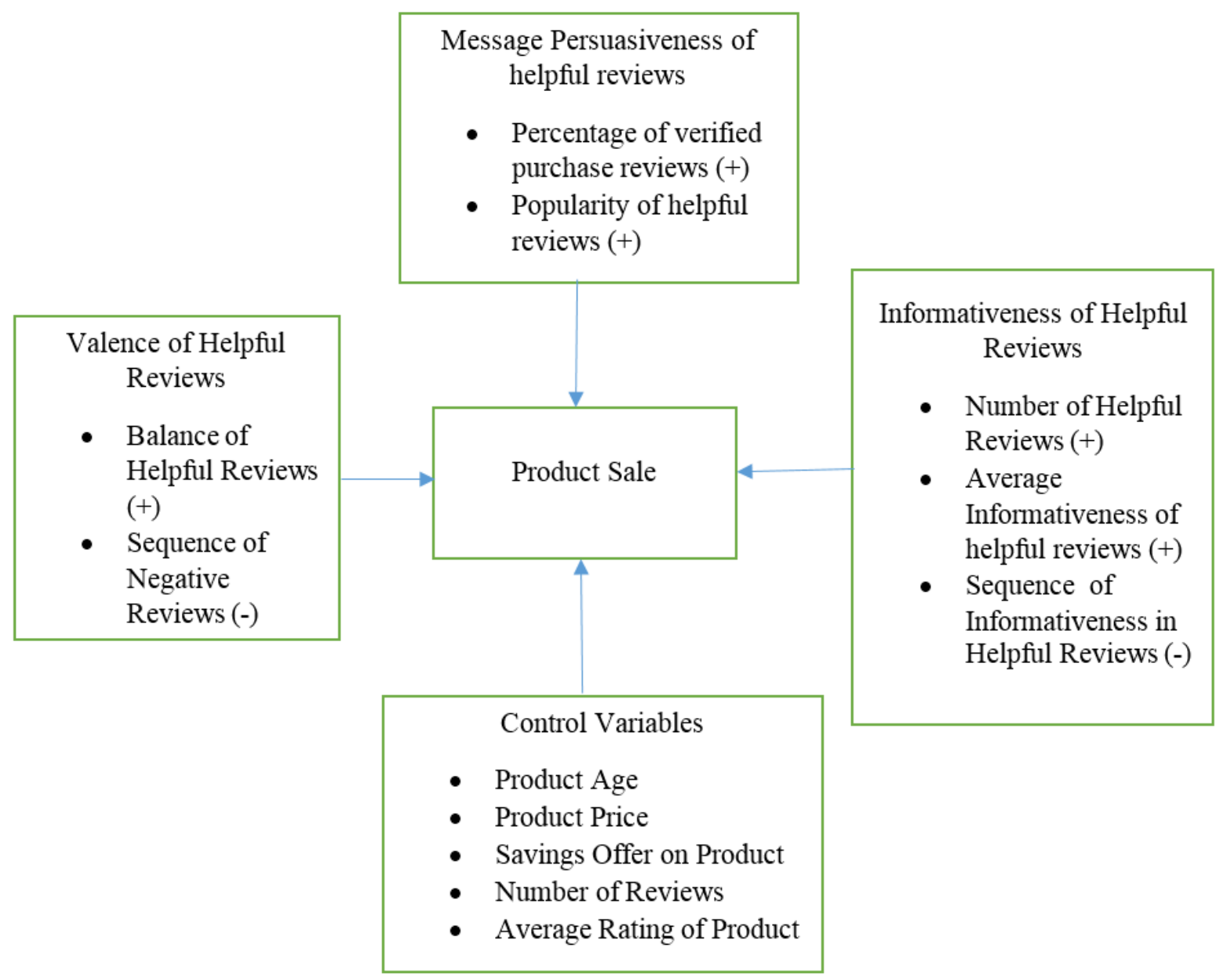

Figure 2. Conceptual Framework

\subsection{Role of Review Informativeness}

The role of number and length of the messages in e-WOM has also being explored in the literature. Some studies suggest that review length positively affects purchase intention (Shelat \& Egger, 2002), as long reviews contain detailed information about the product (Mudambi \& Schuff, 2010). Liu \& Park (2015) found that review length has positive influence on the usefulness of the review. While on the other hand, some other studies suggest that lengthy messages are complex and more difficult to understand ( $\mathrm{Li}$ et al., 2016). Chevalier \& Mayzlin (2006) found that average length of reviews negatively influences the product sales. Although there is debate about effect of reviews length and number of reviews on product sales, there is consensus in research community that 
informativeness of reviews positively influences the purchase intention and facilitates better decision making. Informativeness refers to the amount of information about distinct features of phone conveyed by the review. Thus for helpful reviews available on the product page informativeness has two aspects i.e. number of helpful reviews and content in helpful reviews. Park \& Lee (2009) argued that more number of reviews leads to higher perceived informativeness as there are more facts supporting product recommendation. Thus, products with higher number of helpful reviews displayed on product page would have more sales during next week.

H1: Number of helpful reviews displayed on product page positively influences the product sales.

Other than number of helpful reviews, content in helpful reviews would also influence informativeness. The number of unique tokens excluding English stopwords is a good representative of unique content in review. It computes the number of attributes and features discussed about the product in the review. We refer to number of unique tokens excluding English stopwords as informativeness of review. Building on the same premise, we argue that review set having higher average distinct keywords per review would be considered as more informative than one with lower average distinct keywords per review. Park \& Lee (2009) also argued that irrespective of reviews sentiment, information content in the review set positively influences the purchase intention. When more information is available to user, they are better informed about various features of products that help in purchase related decision making. Thus, we propose the following hypothesis that products having helpful review set with higher average information content would be having higher sales.

H2: Average informativeness of helpful reviews positively influences the product sales.

There exists too much information on online platforms. Excess of information on online platforms engenders information overload phenomenon (Malhotra, 1984). Exposure to excess of information generates cognitive overload among users. Arrangement of reviews on product page is likely to affect the arousal of cognitive overload. Cognitive overload happens when upcoming information is of no significance to the user. We argue that cognitive overload would come earlier for a review set that contains more information in initial reviews than later reviews. We propose to divide the 
helpful reviews available on product page into two sections i.e. first-half and second-half. If average length of helpful reviews in first-half is higher than average length of helpful reviews in second-half, the first-half of review set is conveying more information than second-half of review set. We argue that information overload would come earlier for review set with higher average length in first-half of reviews as compared to review set that has less average length of reviews in first-half. Information overload dampens the decision making process of user ( $\mathrm{Li}$ et al., 2016). Hence, we propose that products whose helpful review set has higher informativeness in first-half of reviews would have lower sales as compared to products that have review set with lower informativeness in first-half of reviews.

H3: Products with higher average informativeness in first-half of reviews are likely to have lower sales as compared to products having lower average informativeness in second-half of reviews.

\subsection{Message Persuasiveness of Helpful Reviews}

In this section, we have proposed the hypothesis related to persuasiveness of helpful reviews. Persuasiveness of reviews have two dimensions namely, source credibility and popularity of the review (Petty \& Cacioppo, 2012). Hypothesis for these two aspects of persuasiveness are proposed separately in following sub-sections.

Source Credibility: Helpful reviews also have a tag attached to it named "verified purchase” (see Figure 3) on Amazon website. This indicates that review is written by a person who has bought the product from this platform. It generates the belief among readers that the person who has written the review has bought the product and also has experience of using the product. If the review is coming from an authentic user then it builds the credibility of the review content in the mind of the readers (Flanagin \& Metzger, 2013). Hence, the review is credible. Thus, higher the percentage of verified purchase reviews in helpful reviews, readers would perceive the reviews to be more authentic and credible. As suggested by message persuasion theory (Petty \& Cacioppo, 2012), a belief in authenticity and credibility of review would lead to favourable perception about the product. Hence, we propose the following hypothesis:

H4: Percentage of verified reviews on product page positively influences the product sales. 


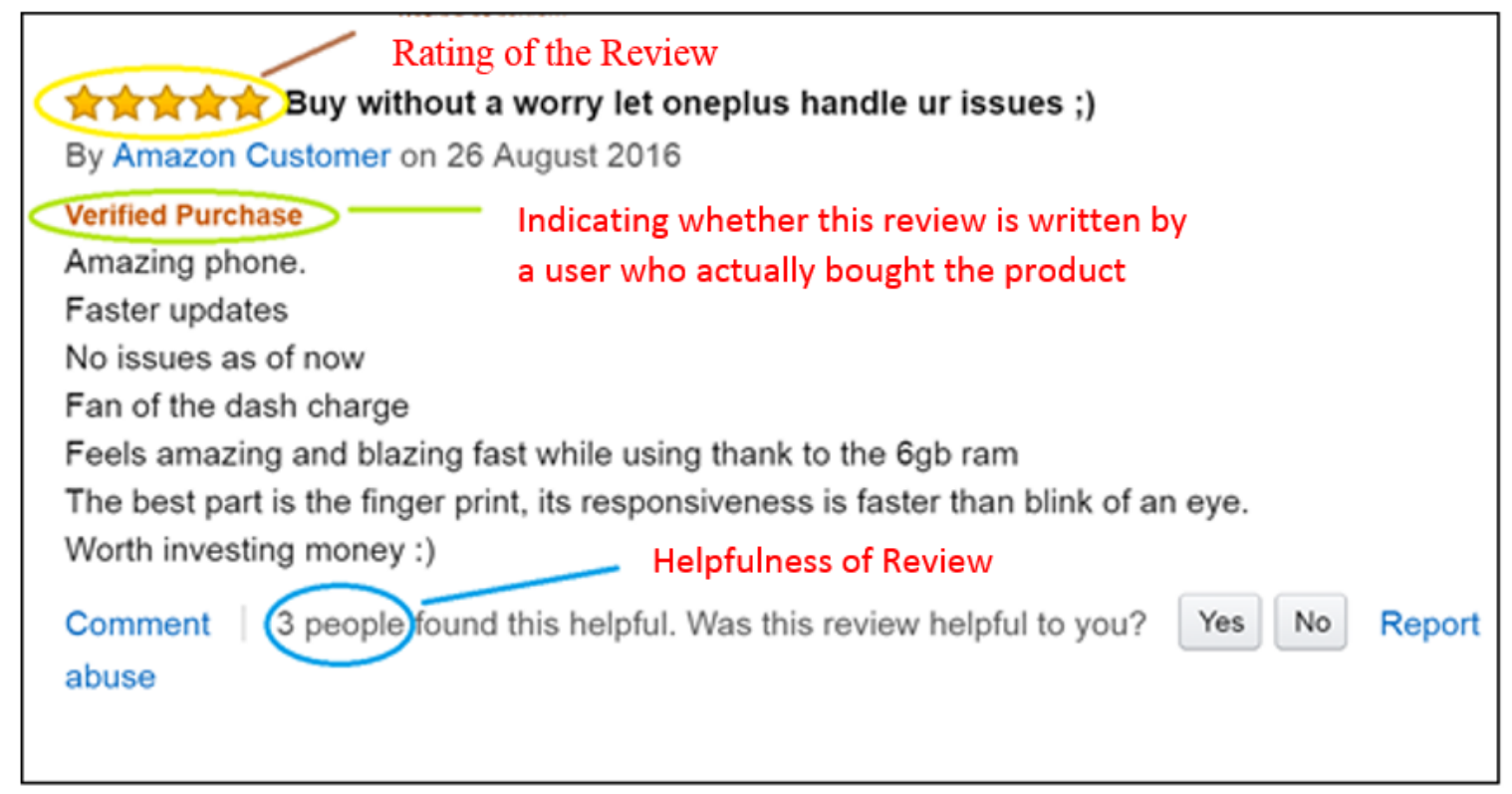

Figure 3. Various Features of Helpful Reviews

Usefulness/popularity of helpful reviews: The online market platform enables users to express their opinion about reviews. It is a form of multi-level word-of-mouth (i.e. WOM about WOM of a product). At Amazon platform, users can also express their view about a review by clicking in favour of it. This feature in Amazon is called helpfulness of the review. Amazon displays how many users have found a particular review helpful (see Figure 3). Thus, helpfulness of a review represents two aspects of the reviews that are information usefulness and its popularity. Reviews that are found helpful by many users are having useful information about the product. Another aspect i.e. popularity represents the indirect word-of-mouth of a product. It enhances the belief about utility and popularity of reviews. Hence, we propose the following hypothesis:

H5: Helpfulness Count of helpful reviews should positively influence the product sales.

\subsection{Balance and Sequence Helpful Reviews}

On the product page, the user is exposed to helpful reviews. Helpful reviews represent mixed information (positive and negative) about a product. In a review set, balance is referred as net positive sentiment conveyed by the review set. In our study, we are taking difference between number of positive and negative reviews in helpful reviews set as proxy of Balance. The balance of reviews affects product sale (Cui et al., 2012). Review set with more positive reviews is likely 
to create favourable impression in consumer's mind about the product that would lead to higher purchase intention. Hence, we propose the following hypothesis:

H6: Balance of helpful reviews should positively affect product sales.

The user goes through helpful reviews from top to down. Literature suggests that message order impacts final judgments of the customer about a product (Haugtvedt \& Wegener, 1994). Belief adjustment model (Hogarth \& Einhorn, 1992) also suggests that message order affects the persuasiveness of message set. In a case of mixed information (positive and negative), the sequence of helpful reviews may also impact the decision-making process of users. In persuasion literature, the effect of presentation order of messages on individual's judgment is widely studied. When initial messages have more impact on decision-making process, it is considered as primacy effect. If messages presented at the end of the list have more impact on individual's decisionmaking, then it is called recency effect.

Message presentation order studies have found both primacy (Zhao, 1997) and recency effect (Carlson \& Russo, 2001). Murphy, Hofacker, \& Mizerski (2006) found the prevalence of primacy effect in the online environment. Some psychological studies have suggested the role of other factors such as consumer involvement, customer motivation, message relevance, message polarity (positive or negative) in position effects (Murphy et al., 2006). Analysing the role of message relevance, Haugtvedt \& Wegener (1994) found that higher level of relevance leads to higher primacy effect and lower level of message relevance leads to higher recency effect. In an experiment by Mollet \& Harrison (2007), subjects recalled more negative words than positive words; thus suggesting that negative information persists memory trace and is of greater importance to people. In the case of positive information, the consumer gives less relevance to it. Hence, it can be argued that people would give more importance to negative reviews and sequence of negative reviews affects the product sales. For information with higher relevance, primacy effect may prevail (Haugtvedt \& Wegener, 1994). Hence, the information given for the initial set of reviews would play a critical role in forming the impression in consumer's mind, and it will reinforce primacy effect. We have theorized for the effect of the sequence of negative reviews using following two cases.

Case 1: First-half of helpful reviews has more negative reviews than second-half 
Case 2: First-half of helpful reviews has lesser negative reviews than second-half

For Case 1, first-half contains more negative information than the second-half, so the user should have a more negative impression about the product than products with Case 2 due to primacy effect. Hence, products with Case 1 should have a lesser sales than products in Case 2. We would like to propose following hypothesis:

H7: Products having more negative reviews in the first-half are likely to have lower sales as compared to products having lesser number of negative reviews in first-half.

\section{Research Methodology}

In this section, we would discuss about the data collection procedure and quantitative technique adopted for testing the proposed hypothesis. Along with data collection procedure, process of extracting key variables and summary statistics is also described.

\subsection{Data Collection}

We have collected the data from amazon.in platform for various products as Amazon website provides a rich collection of the reviews. Amazon data has also been utilized in the previous studies (e.g., Chong et al., 2016; Dhar \& Chang, 2009) as well to analyse the effect of WOM on product sales. We have selected a product category that has a good level of involvement. For example, electronics category, e-WOM plays a major role in decision-making (Salehan \& Kim, 2016) and there exist studies that have examined the impact of reviews on purchase intention for electronics category (Chong et al., 2016). Within the electronic category, we selected smart phone products. We have selected smartphones, because it is high involvement product for which consumers relies on reviews to purchase related decisions (Cui et al., 2012). It is one of the largest selling products in electronics category at amazon.in. Studies focused on specific products with concrete implications for marketers are more relevant to the research community and practitioners (De Maeyer, 2012). As the goal of our research was to examine the effect of helpful reviews on sales, so we decided to select only those products that have at least some reviews on its product page. First, we selected 100 mobiles that are displayed under hot new releases category on amazon.in. We further selected only those products that were launched in past three months from $1^{\text {st }}$ January 2016. We crawled data from product pages of these mobiles for nine months on a weekly basis. 
First, we downloaded product pages for these products using $\mathrm{R}$ Week-by-Week. Then, we extracted relevant variables from these downloaded pages using XML package in R. From mobile phones, we selected only smartphones for further analysis. SaleRank for each smartphone in “Electronics $>$ Mobiles \& Tablets $>$ Smartphones \& Basic Mobiles > Smartphones” category was captured from product page at amazon.in. Input variables and control variables are captured from product pages using HTML parser and extractor in R. Previous studies have used Amazon SaleRank for capturing the product sales on Amazon platform (Judith a Chevalier \& Mayzlin, 2006; Chong et al., 2016). SaleRank denotes where a product sale stands as compared to other products in that category. We have taken - $\log ($ SaleRank) as proxy of product sales (Cui et al., 2012).

Table 2. Variables and their description

\begin{tabular}{|c|c|c|}
\hline S. No. & Variable & Description \\
\hline \multicolumn{3}{|c|}{ Dependent Variable } \\
\hline 1 & Sale & $\begin{array}{l}\text { Negative logarithm of product's sale rank given on product } \\
\text { page. }\end{array}$ \\
\hline \multicolumn{3}{|c|}{ Control Variables } \\
\hline 2 & SalePrice & Price of the product \\
\hline 3 & Savings & Amount on saving given on MRP \\
\hline 4 & $\begin{array}{l}\text { Product Age in Weeks } \\
\text { (Age_Week) }\end{array}$ & $\begin{array}{l}\text { Number of weeks the product have been available on } \\
\text { Amazon.in. We took timestamp of oldest review of the product } \\
\text { as proxy of launch timestamp on Amazon.in }\end{array}$ \\
\hline 5 & Average Rating (Rating) & Average Rating of product \\
\hline 6 & Number of reviews (Volume) & Number of total reviews \\
\hline \multicolumn{3}{|c|}{$\begin{array}{c}\text { Independent Variables } \\
\end{array}$} \\
\hline 7 & $\begin{array}{l}\text { Percentage of verified purchase } \\
\text { reviews (HVPP) }\end{array}$ & Percentage of Verified Purchase reviews among helpful reviews \\
\hline 8 & $\begin{array}{l}\text { Helpfulness count of helpful } \\
\text { reviews (Helpfulnum) }\end{array}$ & Helpful count of all the helpful reviews \\
\hline 9 & $\begin{array}{l}\text { Balance of helpful reviews } \\
\text { (Balance) }\end{array}$ & $\begin{array}{l}\text { Balance refers to net positive reviews in helpful review (positive } \\
\text { reviews-negative reviews). Review can have a rating from } 1 \text { to } \\
5.1 \text { being the lowest and } 5 \text { being the highest. Review with more } \\
\text { than } 3 \text { rating is considered as positive. Review with rating } 1 \text { or } \\
2 \text { is considered as negative }\end{array}$ \\
\hline 10 & $\begin{array}{l}\text { Sequence of negative reviews in } \\
\text { Helpful review set (HRNseq) }\end{array}$ & $\begin{array}{l}\text { Sequence of negative reviews ( } 1 \text { =first-half of helpful reviews } \\
\text { have more negative reviews than second-half of reviews, } \\
\text { otherwise }=0 \text { ) }\end{array}$ \\
\hline 11 & $\begin{array}{l}\text { Number of helpful reviews } \\
\text { displayed on product page (HNum) }\end{array}$ & Number of Helpful reviews \\
\hline 12 & $\begin{array}{l}\text { Average informativeness of helpful } \\
\text { reviews displayed on product page } \\
\text { (HAvgIR) }\end{array}$ & $\begin{array}{l}\text { Average Information volume of Helpful reviews. We are } \\
\text { computing it as an average number of unique words in helpful } \\
\text { reviews. We are excluding English stop words from the count }\end{array}$ \\
\hline 13 & $\begin{array}{l}\text { Sequence of Informativeness } \\
\text { among helpful review set (HIRseq) }\end{array}$ & $\begin{array}{l}\text { Sequence of Informativeness in helpful reviews ( } 1 \text { =first-half of } \\
\text { helpful reviews have more content than second-half of reviews, } \\
\text { otherwise }=0 \text { ) }\end{array}$ \\
\hline
\end{tabular}


From smartphones, we filtered smartphones from this category. It shows the relative sales of a product to other products in category. Brief description of all the variables and descriptive statistics are given in Table 2 and Table 3 respectively.

Table 3. Descriptive Summary of Variables

\begin{tabular}{|l|c|c|c|}
\hline \multicolumn{4}{|c|}{ Metric Variables } \\
\hline Variable & Min & Max & Mean \\
\hline Sale Price & Rs. 1600 & Rs. 87600 & Rs. 29809 \\
\hline Average Rating (out of 5) & 1.80 & 4.70 & 3.78 \\
\hline No. of Reviews & 3 & 4027 & 279.7 \\
\hline SaleRank & 4 & 2926 & 316 \\
\hline Percentage of verified Reviews & 0 & 1 & 0.6 \\
\hline Helpfulness Count & 0 & 1739 & 138.10 \\
\hline Balance & -8 & 8 & 3.25 \\
\hline Number of Helpful Reviews & 2 & 8 & 6.29 \\
\hline $\begin{array}{l}\text { Average Informativeness of Helpful } \\
\text { Reviews }\end{array}$ & 3.66 & 165 & 57.23 \\
\hline \multicolumn{2}{|c|}{ Binary Variables } \\
\hline & 1 & 0 & \\
\hline HRNseq & $76.50 \%$ & $23.50 \%$ & \\
\hline HIRSeq & $76.71 \%$ & $23.29 \%$ & \\
\hline
\end{tabular}

\subsection{Data Analysis}

To test the relationships proposed in our theoretical model, we have used linear regression model given in Equation 1. We have used lagged dependent variable as prescribed by (Cui et al., 2012) to control for endogenity. We ran the regression between the content of product page and next week sales of the product. In this study, we have used 8 input variables and five control variables (Savings, Price, Product age, Number of Reviews on product page, Average Rating of Product) and one dependent variable (Sale).

Empirical Model:

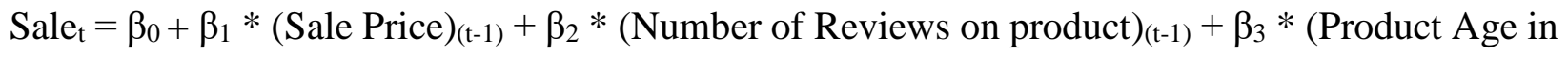

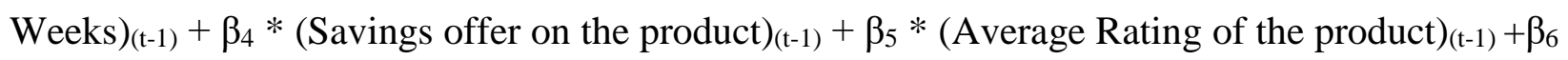
* (No. of helpful reviews) $)_{(\mathrm{t}-1)}+\beta_{7} *$ (Average Informativeness of helpful reviews) $(\mathrm{t}-1)+\beta_{8} *($ Informativeness Sequence of Helpful Reviews) $)_{(\mathrm{t}-1)}+\beta_{9} *(\%$ of verified purchase reviews)(t-1) + $\beta_{10} *$ (count of Helpfulness of helpful reviews) $)_{(\mathrm{t}-1)}+\beta_{11} *$ (No. of helpful Reviews) $(\mathrm{t}-1)+\beta_{12} *$

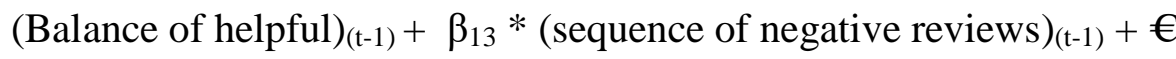




\section{Results \& Discussion}

In this section, we have presented the results of proposed model. Variables such as price, savings, product age, average rating, and number of reviews on product would play a significant role in affecting the final decision of the customer. Hence, these variables have been taken as control variables in all the regression model. Model 1 tests the effect of all the control variables on product sales. It is clear from Table 4 that average rating, savings offer, and number of reviews positively affect the product sales. Product age and sale price negatively affect product sales. Model 2 is used for testing hypotheses 1-7. All the metric independent variables have been standardized before running the regression model. For multicollinearity analysis, VIF score of different variables has been reported in Appendix B. We found support for hypotheses 1 to 7.

\begin{tabular}{|c|c|c|c|c|}
\hline Variables & $\begin{array}{c}\text { Model } 1 \\
\text { Coefficient }\end{array}$ & Std. error & $\begin{array}{c}\text { Model } 2 \\
\text { Coefficient }\end{array}$ & Std. errol \\
\hline (Intercept) & $-2.27 * * *$ & $(0.01)$ & $-2.13^{* * *}$ & $(0.03)$ \\
\hline ZSalePrice & $-0.13 * * *$ & $(0.01)$ & $-0.14 * * *$ & $(0.01)$ \\
\hline ZNoOfReviews & $0.21 * * *$ & $(0.01)$ & $0.19 * * *$ & $(0.01)$ \\
\hline ZAge_Week & $-0.13 * * *$ & $(0.01)$ & $-0.16 * * *$ & $(0.01)$ \\
\hline ZSavings & $0.07 * * *$ & $(0.01)$ & $0.06^{* * *}$ & $(0.01)$ \\
\hline ZAvgRating & $0.06^{* * *}$ & $(0.01)$ & $0.04^{* * *}$ & $(0.01)$ \\
\hline HNum & & & $0.12 * * *$ & $(0.02)$ \\
\hline HAvgIR & & & $0.05^{* * *}$ & $(0.02)$ \\
\hline HIRseq & & & $-0.09 * * *$ & $(0.02)$ \\
\hline ZHVPP & & & $0.05^{* * *}$ & $(0.01)$ \\
\hline ZHelpfulnum & & & $0.05^{* * *}$ & $(0.01)$ \\
\hline ZBalance & & & $0.04^{*}$ & $(0.01)$ \\
\hline HRNseq & & & $-0.09 * * *$ & $(0.02)$ \\
\hline R2 & 0.29 & & 0.36 & \\
\hline adj. R2 & 0.28 & & 0.35 & \\
\hline F-Value & 136.6 & & 78.54 & \\
\hline P statistic for F Value & $2.20 \mathrm{E}-16$ & & $2.20 \mathrm{E}-16$ & \\
\hline \multicolumn{5}{|c|}{$\begin{array}{l}\text { Note: } \mathrm{p} \text {-values are reported next to actual estimates. }{ }^{* * *} \text { for } \mathrm{p}<0.01 \text {, }{ }^{* *} \text { for } \mathrm{p}<0.02,{ }^{*} \text { for } \\
\mathrm{p}<0.05\end{array}$} \\
\hline
\end{tabular}

Consistent with informativeness propositions, we found that number of helpful reviews displayed on product page has positive impact on product sales $\left(0.12^{* * *}\right)$. It reinforces that more number of reviews displayed on page leads to greater informativeness of review set resulting in more product sales. Result suggests that average informativeness of helpful reviews positively affects product sales $\left(0.05^{*}\right)$. Along with informativeness, sequence of informativeness also affects decision making of consumer. In line with the proposed hypothesis, we found that helpful reviews with more content in first-half of reviews are likely to have lower product sales (coefficient 
$($ HIRseq $)=-0.09 * * *)$. It suggests that cognitive overload comes early for a review set with more information in initial reviews.

As proposed, percentage of verified purchase reviews $\left(0.05^{* *}\right)$ and helpful count of helpful reviews $\left(0.05^{* * *}\right)$ positively affect the product sales. It suggests that persuasive characteristics such as source credibility and usefulness/popularity engender favourable attitude in consumer's mind. Amount of net positive reviews i.e. balance have positive impact on product sales $(0.04 * * *)$. Thus amount of positive reviews with respect to negative reviews in review set creates favourable impression about product in consumer's mind. Sequence of negative reviews negatively affects the product sales $(-0.09 * * *)$, suggesting that arrangement of negative reviews is likely to affect the consumer attitude about the product. When negative reviews are distributed more in the firsthalf of a review set, it conveys more negative impression and effect of negative review is more than the scenario when first-half has less negative reviews than second-half.

Thus, we got support for all the hypotheses proposed in this study. The analysis is based on data collected for 57 smartphones over 9 months. Summary of hypothesis supported in this study is given in Table 5. In the following section, we will discuss the theoretical and managerial implications of the results.

Table 5. Hypotheses Summary Table

\begin{tabular}{|c|l|l|}
\hline S. No. & Hypothesis & Result \\
\hline 1 & Informativeness (HNum) $\rightarrow$ Product Sales & Supported \\
\hline 2 & Average Informativeness per review (HAvgIR) $\rightarrow$ Product Sales & Supported \\
\hline 3 & Sequence of Informativeness (HIRseq) $\rightarrow$ Product Sales & Supported \\
\hline 4 & Source Credibility (HVPP) $\rightarrow$ Product Sales & Supported \\
\hline 5 & Usefulness of Helpful reviews (Helpfulnum) $\rightarrow$ Product Sales & Supported \\
\hline 6 & Valence of Helpful reviews (NET) $\rightarrow$ Product Sales & Supported \\
\hline 7 & Sequence of Negative reviews (HRNseq) $\rightarrow$ Product Sales & Supported \\
\hline
\end{tabular}

\section{Implications for Theory and Practice}

There are several key contributions of this study. While previous studies have largely focused on summary statistics of online reviews (Chen, Dhanasobhon, \& Smith, 2008; Chong et al., 2016; Cui et al., 2012; Dhar \& Chang, 2009), there exist scant studies that have explored the role review sequence with respect to valence and content on product sales. Among the few, Purnawirawan (2014) has explored the role reviews sequence on consumer's impression about a product using consumer survey method. This study examines the effect of review sequence using real-world sales data from popular e-commerce platform. It also provides clarity on how message sequence influences consumer's decisions in online environment. As far as the online environment is 
concerned, there are mixed results about the effect of message sequence on the final judgment of customer. Regarding the length of review, Chevalier \& Mayzlin (2006) found both positive and negative influence of review length on product sales. Along with review summary statistics, our model analyses the effect of review sequence and review informativeness on product sales using amazon.in the platform. We have proposed and tested models to examine the effect of various review characteristics and review sequence on product sales. This work also contributes to message order research by examining the position effect of negative information. We found that for negative reviews, primacy effect prevails. This finding is in line with previous studies related message sequence and confirms to the argument that primacy effect prevails for negative information (Haugtvedt \& Wegener,1994; Murphy et al., 2006). Negative reviews create more unfavourable impressions given that there are more reviews in starting of the review set. This work also clarifies the role of review length in online purchase using cognitive overload theory. Rather than length, we theorized upon the concept of informativeness to examine the effect of review length on product sales. It is found that more number of helpful reviews displayed on product page conveys more information about the product to customers. We also find any significant effect of average length of helpful reviews on product length. It suggests that rather both amount and variety of content (supporting various recommendations about the product) is what helps the user in decision making. Sequence of helpful reviews has an impact on decision making by consumer such that review set with more information in initial reviews generates cognitive overload early, resulting in lower product sales. It is advisable to put lengthy reviews in the later part of helpful reviews.

Our research findings show that helpful reviews and review sequence available on product page do have a significant impact on product sales. Our research has several implications for practitioners and managers at e-commerce platforms. Findings in this study would help the content designers to effectively organize the review content on product page. It would help the content managers to organize the helpful reviews on the product page with decision parameters such as review valence, sequence, popularity, credibility, and number. Displaying popular and credible reviews would help the product to garner more sales. Net positive reviews also engender favourable impression in consumer's mind. Position of negative reviews enhances or suppresses the effect of negative reviews. Our study suggests that impact of negative reviews is enhanced when there are more negative reviews in initial part of review set. Thus, negative reviews should 
be arranged such that there are less negative reviews in first-half than second-half. Displaying more number of helpful reviews helps in decision making by brining variety of information to customers. Our study explains various decision variables and their effect on product sales that would help e-commerce platforms to optimally organize the content on the product page. Helpful reviews should be organized such that reviews in first-half contains less information than reviews in second-half to postpone the arousal of cognitive overload in consumer's mind.

\section{Conclusion}

This study brings useful insights about the effect of helpful reviews on product sales. We have critically examined the sequence of reviews and other review characteristics with respect to its impact on sales. In this work, an exhaustive model depicting the relationship between various characteristics of helpful reviews and product sales has been built. It includes various dimensions of helpful reviews, volume, balance, informativeness, and sequence. The study contributes to eWOM literature by examining the effect of informativeness and sequence of helpful reviews given on product page. Along with traditional review metrics, the effect of new metrics such as valence sequence and informativeness sequence has been explored. The study has captured various features of helpful reviews to test various hypotheses proposed in our study. In line with previous studies (e.g. Cui et al., 2012), this study also confirms the positive affect of balance of reviews on product sales. It has been found that volume is more influential than balance. Previous studies have also found the most prominent effect of volume of reviews on product sales (Davis \& Khazanchi, 2008). It suggests that larger number of reviews presents the reliability of the product and engender trust among user (Chong et al., 2016). Larger number of helpful reviews also conveys more information about the product to customer. Source credibility and reviews popularity/usefulness play a very important role in product sales. As proposed, it has been found that net positive reviews in helpful reviews positively affect the product sales. This study makes a significant contribution to resolving the controversy about the role of length of reviews. Some studies found the negative impact of length on product sales, while other argued for the positive effect of it product favourability. We approach this phenomenon with informativeness perspective and found that both

information content (average length of reviews) and variety of information in helpful reviews (number of reviews) affect the perceived informativeness and product sales. However, 
arrangement of information in review set may affect the arousal of cognitive overload. More information in initial reviews may lead to early arrival of cognitive overload.

We also analysed the impact of the sequence of reviews on product sales. Previous studies on online environment suggested the prevalence of primacy effect in the influence of message order on purchase intention. Considering psychological studies, we proposed that people give more importance to negative information. In a case of high relevance messages, primacy effect may be more prominent. As per the proposed hypothesis, we found that negative reviews have primacy effect. Products that have more negative reviews in first-half of helpful reviews would lead to have lower product sales.

This study has few limitations from dataset and methodology perspective. At amazon.in platform, we could not get sufficient items through other electronics products. So we restricted our focus to mobile products. Future studies may compare the effect of these review features across various product categories. Other than this, our results are valid for across the products comparison. These results may not be valid for predicting the sales of a product across the time. We have also not examined the effect of review features on product sales at individual product level rather focused on the phenomena at the aggregate level. In future work, these limitations can be addressed. Moreover, this study has only examined the helpful reviews on the products' sales on Amazon website, but not linked with the consumers' attitude and adoption behavior of such websites using technology adoption models (Alalwan et al., 2015, 2016, 2017, 2018; Alryalat et al., 2015; Dwivedi et al., 2017a, 2017b; Rana and Dwivedi, 2015, 2016; Rana et al., 2016, 2017). The future research could explore the electronic production adoption from the Amazon website.

\section{References}

Alalwan, A.A., Dwivedi, Y.K. \& Rana, N.P.*, Algharabat, R.S. (2018). Examining Factors Influencing Jordanian Customers’ Intentions and Adoption of Internet Banking: Extending UTAUT2 with Risk. Journal of Retailing and Consumer Services, 40, 125-138.

Alalwan, A.A., Dwivedi, Y.K., \& Rana, N.P. (2017). Factors Influencing Adoption of Mobile Banking by Jordanian Bank Customers: Extending UTAUT2 with Trust. International Journal of Information \& Management, 37(3), 99-110.

Alalwan, A.A., Dwivedi, Y.K., Rana, N.P., \& Williams, M.D. (2016). Consumer adoption of mobile banking in Jordan: Examining the role of usefulness, ease of use, perceived risk and self-efficacy. Journal of Enterprise Information Management, 29(1), 118-139.

Alalwan, A.A., Dwivedi, Y.K., Rana, N.P., Lal, B., \& Williams, M.D. (2015). Consumer Adoption of Internet Banking in Jordan: Examining the Role of Hedonic Motivation, Habit, SelfEfficacy and Trust. Journal of Financial Services Management, 20(2), 145-157. 
Alryalat, M., Rana, N.P., \& Dwivedi, Y.K. (2015). Citizen’s adoption of an e-government system: Validating the extended theory of reasoned action (TRA). International Journal of Electronic Government Research, 11(4), 1-23.

Buda, R., \& Zhang, Y. (2000). Consumer product evaluation: the interactive effect of message framing, presentation order, and source credibility. Journal of Product \& Brand Management, 9(4), 229-242. http://doi.org/10.1108/10610420010344022.

Carlson, K. a, \& Russo, J. E. (2001). Biased interpretation of evidence by mock jurors. Journal of Experimental Psychology: Applied, 7(2), 91-103. http://doi.org/10.1037/1076-898X.7.2.91

Chen, P., Dhanasobhon, S., \& Smith, M. D. (2008). All Reviews are Not Created Equal: The Disaggregate Impact of Reviews and Reviewers at Amazon.com. In Heinz College Research (pp. 1-32). http://doi.org/10.2139/ssrn.918083

Chevalier, J., \& Mayzlin, D. (2006). The effect of word of mouth on sales: Online book reviews. Journal of Marketing Research, 43(3), 345-354.

Chintagunta, P. (2010). The effects of online user reviews on movie box office performance: Accounting for sequential rollout and aggregation across local markets. Marketing Science, 29(5), 944-957.

Chong, A., Li, B., Ngai, E., \& Ch’ng, E. (2016). Predicting online product sales via online reviews, sentiments, and promotion strategies: A big data architecture and neural network approach. International Journal of Operations \& Production Management, 36(4), 358-383.

Clemons, E. K., Gao, G. G., \& Hitt, L. M. (2006). When Online Reviews Meet A Study of the Hyperdifferentiation: Craft Beer Industry. Journal of Management Information Systems, 23(2), 149-171. http://doi.org/10.2753/MIS0742-1222230207

Cui, G., Lui, H.-K., \& Guo, X. (2012). The Effect of Online Consumer Reviews on New Product Sales. International Journal of Electronic Commerce, 17(1), 39-58. http://doi.org/10.2753/JEC1086-4415170102

Davis, A., \& Khazanchi, D. (2008). An Empirical Study of Online Word of Mouth as a Predictor for Multi-product Category e-Commerce SalesAn Empirical Study of Online Word of Mouth as a Predictor for Multi-product Category e-Commerce Sales. Electronic Markets, 18(2), 130-141. http://doi.org/10.1080/10196780802044776

De Maeyer, P. (2012). Impact of online consumer reviews on sales and price strategies: a review and directions for future research. Journal of Product \& Brand Management, 21(2), 132-139. http://doi.org/10.1108/10610421211215599

Dellarocas, C. N., Awad, N., \& Zhang, X. (Michael). (2004). Using Online Reviews as a Proxy of Word-of-Mouth for Motion Picture Revenue Forecasting. SSRN Electronic Journal. http://doi.org/10.2139/ssrn.620821

Dhar, V., \& Chang, E. A. (2009). Does Chatter Matter? The Impact of User-Generated Content on Music Sales. Journal of Interactive Marketing, 23(4), 300-307. http://doi.org/10.1016/j.intmar.2009.07.004

Dixit, S., Badgaiyan, A. J., \& Khare, A. (2017). An integrated model for predicting consumer's intention to write online reviews. Journal of Retailing and Consumer Services, DOI: 10.1016/i.jretconser.2017.10.001. 
Duan, W., Gu, B., \& Whinston, a. (2008a). The dynamics of online word-of-mouth and product sales-An empirical investigation of the movie industry. Journal of Retailing, 84(2), 233242. http://doi.org/10.1016/j.jretai.2008.04.005

Duan, W., Gu, B., \& Whinston, A. (2008b). Do online reviews matter?-An empirical investigation of panel data. Decision Support Systems, 45(4), 1007-1016.

Dwivedi, Y.K., Rana, N.P., and Janssen, M., Lal, B., Williams, M.D., \& Clement, M. (2017). An Empirical Validation of a Unified Model of Electronic Government Adoption (UMEGA). Government Information Quarterly, 34(2), 211-230.

Dwivedi, Y.K., Rana, N.P., Jeyaraj, A., Clement, M., \& Williams, M.D. (2017). Re-examining the Unified Theory of Acceptance and Use of Technology (UTAUT): Towards a Revised Theoretical Model. Information Systems Frontiers, DOI: 10.1007/s10796-017-9774-y.

Flanagin, A. J., \& Metzger, M. J. (2013). Trusting expert versus user-generated ratings online: The role of information volume, valence, and consumer characteristics. Computers in Human Behavior, 29(4), 1626-1634. http://doi.org/10.1016/j.chb.2013.02.001

Forman, C., \& Ghose, A. (2008). Examining the relationship between reviews and sales: The role of reviewer identity disclosure in electronic markets. Information Systems Research , 19(3), 291-313.

Ghose, A., \& Ipeirotis, P. G. (2010). Estimating the Helpfulness and Economic Impact of Product Reviews. Ieee Transactions on Knowledge and Data Engineering, 23(10), 1498-1512. http://doi.org/10.1109/TKDE.2010.188

Haugtvedt, C. P., \& Wegener, D. T. (1994). Message Order Effects in Persuasion: An Attitude Strength Perspective. Journal of Consumer Research, 21(1), 205-218. http://doi.org/10.1086/209393

Hiltz, S. R., \& Turoff, M. (1985). Structuring Computer-Mediated Communication Systems To Avoid Information Overload. Communications of the ACM, 28(7), 680-689. http://doi.org/10.1145/3894.3895

Hogarth, R., \& Einhorn, H. (1992). Order effects in belief updating: the belief-adjusting model. Cognitive Psychology, 24(1), 1-55.

Hu, N., Koh, N. S., \& Reddy, S. K. (2014). Ratings lead you to the product, reviews help you clinch it? The mediating role of online review sentiments on product sales. Decision Support Systems, 57, 42-53. http://doi.org/10.1016/j.dss.2013.07.009

Hu, N., Liu, L., \& Zhang, J. J. (2008). Do online reviews affect product sales? The role of reviewer characteristics and temporal effects. Information Technology and Management, 9(3), 201214. http://doi.org/10.1007/s10799-008-0041-2

Jones, Q., Ravid, G., \& Rafaeli, S. (2004). Information Overload and the Message Dynamics of Online Exploration Information Overload and the Message Dynamics of Online Interaction Spaces: A Theoretical Model and Empirical Exploration. Information Systems Research, 15(2), 194-210. http://doi.org/10.1287/isre.1040.0023

Jones, Q., Ravid, G., \& Rafaeli, S. (2004). Information overload and the message dynamics of online interaction spaces: A theoretical model and empirical exploration. Information Systems 
Research, 15(2), 194-210.

Jones, Q., Ravid, G., \& Rafaeli, S. (2010). Information Overload and the Message Dynamics of Online Interaction Spaces: A Theoretical Model and Empirical Exploration. IEEE Engineering Management Review.

Kirsh, D. (2000). A few thoughts on cognitive overload. Intellectica. http://doi.org/10.1128/AAC.03728-14

Krosnick, J. A., \& Alwin, D. F. (1987). An Evaluation of a Cognitive theory of response order effects in survey measurement. Public Opinion Quarterly, 51(2), 201-219. http://doi.org/10.1086/269029

Lee, E., \& Shin, S. (2014). When do consumers buy online product reviews? Effects of review quality, product type, and reviewer's photo. Computers in Human Behavior, 31, 356-366.

Li, M., Kankanhalli, A., \& Kim, S. H. (2016). Which ideas are more likely to be implemented in online user innovation communities? An empirical analysis. Decision Support Systems, 84, 28-40. http://doi.org/10.1016/j.dss.2016.01.004.

Liu, Y. (2006). Word of mouth for movies: Its dynamics and impact on box office revenue. Journal of Marketing, 70(3), 74-89.

Liu, Z., \& Park, S. (2015). What makes a useful online review? Implication for travel product websites. Tourism Management, 47, 140-151. http://doi.org/10.1016/j.tourman.2014.09.020

Malhotra, N. (1984). Reflections on the information overload paradigm in consumer decision making. Journal of Consumer Research, 10(4), 436-440.

Mollet, G., \& Harrison, D. (2007). Affective verbal learning in hostility: An increased primacy effect and bias for negative emotional material. Archives of Clinical Neuropsychology, 22(1), 53-61.

Mudambi, S. M., \& Schuff, D. (2010). What makes a helpful review? A study of customer reviews on Amazon. com. MIS Quarterly, 34(1), 185-200.

Murphy, J., Hofacker, C., \& Mizerski, R. (2006). Primacy and Recency Effects on Clicking Behavior. Journal of Computer-Mediated Communication, 11(2), 522-535. http://doi.org/10.1111/j.1083-6101.2006.00025.x

Park, D., \& Lee, J. (2009). eWOM overload and its effect on consumer behavioral intention depending on consumer involvement. Electronic Commerce Research and Applications, 7(4), 386-398.

Petty, R., \& Cacioppo, J. (2012). Communication and persuasion: Central and peripheral routes to attitude change.

Plotkina, D., \& Munzel, A. (2016). Delight the experts, but never dissatisfy your customers! A multi-category study on the effects of online review source on intention to buy a new product. Journal of Retailing and Consumer Services, 29, 1-11.

Purnawirawan, N. (2014). Expert Reviewers Beware! The Effects of Review Set Balance, Review Source and Review Content On Consumer Responses to Online Reviews. Journal of Electronic Commerce Research, 15(3), 162.

Purnawirawan, N., De Pelsmacker, P., \& Dens, N. (2012). Balance and Sequence in Online Reviews: How Perceived Usefulness Affects Attitudes and Intentions. Journal of Interactive 
Marketing, 26(4), 244-255. http://doi.org/10.1016/j.intmar.2012.04.002

Purnawirawan, N., Dens, N., \& De Pelsmacker, P. (2012). Balance and Sequence in Online Reviews: The Wrap Effect. International Journal of Electronic Commerce, 17(2), 71-98. http://doi.org/10.2753/JEC1086-4415170203.

Rana, N.P., \& Dwivedi, Y.K. (2015). Citizen's adoption of an e-government system: Validating extended social cognitive theory (SCT). Government Information Quarterly, 32(2), 172-181.

Rana, N.P., \& Dwivedi, Y.K. (2016). Using clickers in a Large Business Class: Examining Use Behavior and Satisfaction. Journal of Marketing Education, 38(1), 47-64.

Rana, N.P., Dwivedi, Y.K., Lal, B., Williams, M.D., \& Clement, M. (2017). Citizens’ Adoption of an Electronic Government System: Toward a Unified View. Information Systems Frontiers, 19(3), 549-568.

Rana, N.P., Dwivedi, Y.K., Williams, M.D., \& Weerakkody, V. (2016). Adoption of Online Public Grievance Redressal System in India: Toward Developing a Unified View. Computers in Human Behavior, 59, 265-282.

Roy, P.K., Singh, J.P., Baabdullah, A., Kizgin, H., \& Rana, N.P. (2018). Identifying Reputation Collectors in Community Question Answering (CQA) sites: An Exploration of the Dark Side of Social Media. International Journal of Information Management, 42, 25-35.

Salehan, M., \& Kim, D. J. (2016). Predicting the performance of online consumer reviews: A sentiment mining approach to big data analytics. Decision Support Systems, 81, 30-40. http://doi.org/10.1016/j.dss.2015.10.006.

Saumya, S., Singh, J.P., Baabdullah, A., Rana, N.P. and Dwivedi, Y.K. (2018). Ranking Online Consumer Reviews: The Case of Amazon and Snapdeal. Electronic Commerce Research and Applications, 29, 78-89.

Shelat, B., \& Egger, F. N. (2002). What makes people trust online gambling sites? In CHI '02 extended abstracts on Human factors in computing systems - CHI '02 (pp. 852-853). http://doi.org/10.1145/506443.506631

Singh, J.P., Irani, S., Rana, N.P., Dwivedi, Y.K., Saumya, S., and Roy, P.K. (2017). Predicting the "helpfulness" of online consumer reviews. Journal of Business Research, 70, 346-355.

Weisstein, F. L., Song, L., Andersen, P., \& Zhu, Y. (2017). Examining impacts of negative reviews and purchase goals on consumer purchase decision. Journal of Retailing and Consumer Services, 39, 201-207.

Zhao, X. (1997). Clutter and serial order redefined and retested. Journal of Advertising Research, 37(5), 57-74.

Zhu, F., \& Zhang, X. (2010). Impact of Online Consumer Reviews on Sales : The Moderating Role of Product and Consumer Characteristics. Journal of Marketing, 74(2), 133-148.

\begin{tabular}{|c|c|c|c|c|}
\hline \multicolumn{5}{|c|}{ Appendix A. Result of Robust Regression Model with -log(SaleRank) as DV } \\
\hline Variables & Model 1R & & Model 2R & \\
\hline & Coefficient & Std. error & Coefficient & Std. error \\
\hline (Intercept) & $(-2.26)^{* * *}$ & 0.01 & $(-2.13)^{* * *}$ & 0.03 \\
\hline ZSalePrice & $(-0.13) * * *$ & 0.01 & $(-0.14) * * *$ & 0.01 \\
\hline
\end{tabular}




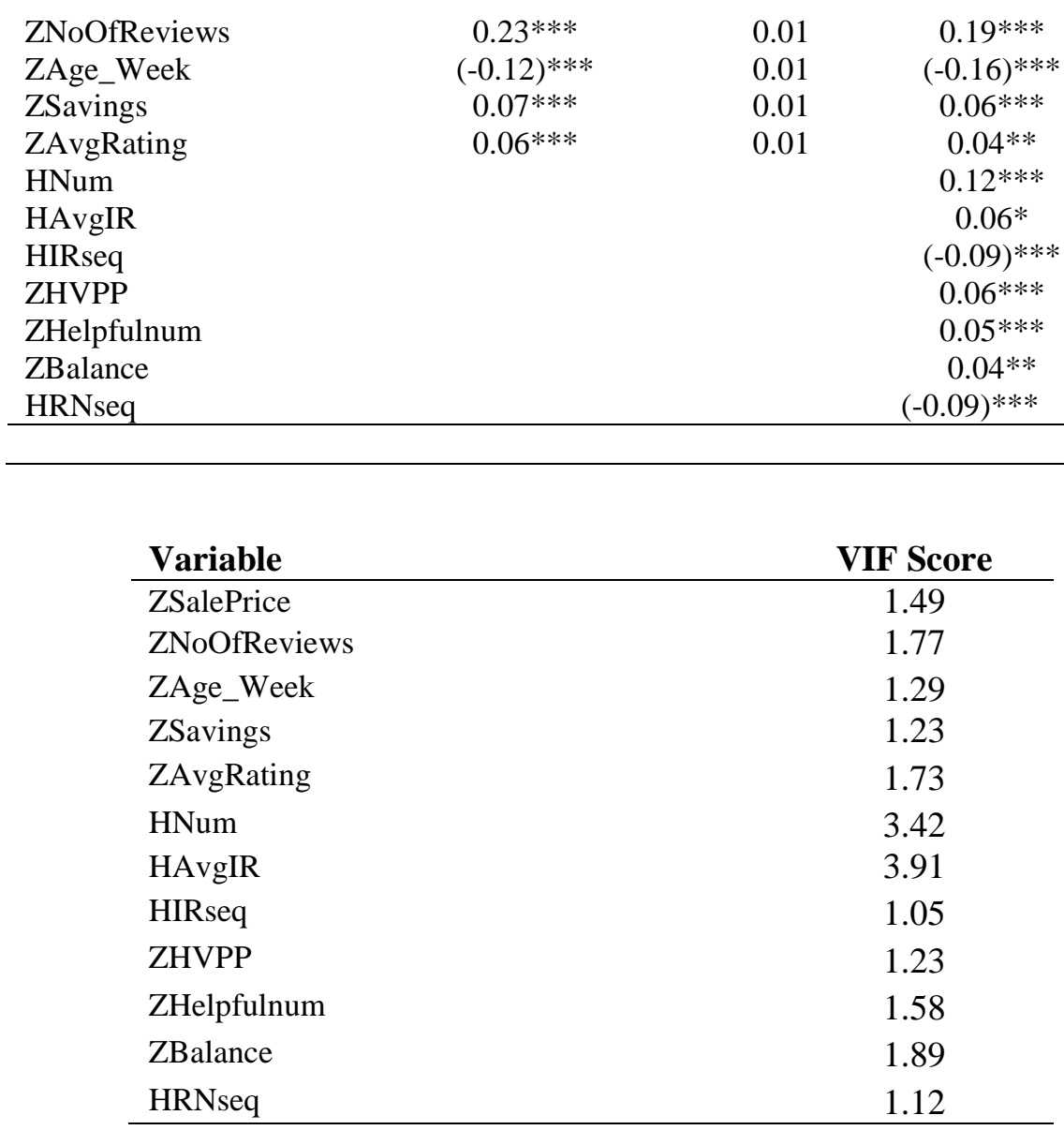

\section{Appendix B: Robustness Checks and Specification Tests}

B.1 Results for testing whether Number of reviews has unit root or not

Null Hypothesis: NOR has a unit root

Exogenous: Constant

Lag Length: 0 (Automatic - based on SIC, maxlag=22)

\begin{tabular}{lrcc}
\hline \hline & t-Statistic & Prob.* \\
\hline \hline Augmented Dickey-Fuller test statistic & -7.569941 & 0.0000 \\
\hline Test critical values: & 1\% level & -3.435449 & \\
& 5\% level & -2.863679 & \\
& 10\% level & -2.567959 & \\
\hline \hline
\end{tabular}

*MacKinnon (1996) one-sided p-values.

Augmented Dickey-Fuller Test Equation

Dependent Variable: D(NOR)

Method: Least Squares

Date: 04/16/18 Time: 13:51

Sample (adjusted): 21234

Included observations: 1231 after adjustments 


\begin{tabular}{lrlrr}
\multicolumn{1}{c}{ Variable } & Coefficient & \multicolumn{1}{c}{ Std. Error } & t-Statistic & Prob. \\
\hline \hline \multicolumn{1}{c}{ NOR(-1) } & -0.047961 & 0.006336 & -7.569941 & 0.0000 \\
\multicolumn{1}{c}{ C } & 9.993090 & 14.68025 & 0.680717 & 0.4962 \\
\hline \hline R-squared & 0.044549 & Mean dependent var & -13.93095 \\
Adjusted R-squared & 0.043772 & S.D. dependent var & 514.3717 \\
S.E. of regression & 502.9882 & Akaike info criterion & 15.28063 \\
Sum squared resid & $3.11 \mathrm{E}+08$ & Schwarz criterion & 15.28895 \\
Log likelihood & -9403.230 & Hannan-Quinn criter & 15.28376 \\
F-statistic & 57.30401 & Durbin-Watson stat & 2.000710 \\
Prob (F-statistic) & 0.000000 & & \\
\hline \hline
\end{tabular}

Null Hypothesis: D(NOR) has a unit root

Exogenous: Constant

Lag Length: 0 (Automatic - based on SIC, maxlag=22)

\begin{tabular}{lrrr}
\hline \hline & t-Statistic & Prob.* \\
\hline \hline Augmented Dickey-Fuller test statistic & -35.09606 & 0.0000 \\
\hline Test critical values: & 1\% level & -3.435458 & \\
& 5\% level & -2.863683 & \\
& 10\% level & -2.567961 & \\
\hline \hline
\end{tabular}

*MacKinnon (1996) one-sided p-values.

Augmented Dickey-Fuller Test Equation

Dependent Variable: D(NOR,2)

Method: Least Squares

Date: 04/16/18 Time: 14:01

Sample (adjusted): 31234

Included observations: 1229 after adjustments

\begin{tabular}{lrlrr}
\hline \hline \multicolumn{1}{c}{ Variable } & Coefficient & Std. Error & t-Statistic & Prob. \\
\hline \hline \multicolumn{1}{c}{ D(NOR(-1)) } & -1.001921 & 0.028548 & -35.09606 & 0.0000 \\
\multicolumn{1}{c}{ C } & -14.01541 & 14.69562 & -0.953713 & 0.3404 \\
\hline \hline R-squared & 0.500963 & Mean dependent var & -0.034174 \\
Adjusted R-squared & 0.500556 & S.D. dependent var & 728.7203 \\
S.E. of regression & 514.9966 & Akaike info criterion & 15.32782 \\
Sum squared resid & $3.25 E+08$ & Schwarz criterion & 15.33615 \\
Log likelihood & -9416.948 & Hannan-Quinn criter. & 15.33095 \\
F-statistic & 1231.733 & Durbin-Watson stat & 2.001637 \\
Prob (F-statistic) & 0.000000 & & \\
\hline \hline
\end{tabular}

\section{B.2 Huber-White-Hinkley (HC1) test results for}

\section{variable SALE}

Dependent Variable: SALE

Method: Least Squares

Date: 04/17/18 Time: 16:38

Sample: 11713 
Included observations: 1712

\begin{tabular}{crcrr}
\hline \hline Variable & Coefficient & Std. Error & t-Statistic & Prob. \\
\hline \hline C & -2.128304 & 0.027374 & -77.75014 & 0.0000 \\
ZSALEPRICE & -0.140920 & 0.011570 & -12.17976 & 0.0000 \\
ZNOOFREVIEWS & 0.190332 & 0.012638 & 15.05975 & 0.0000 \\
ZAGE_WEEK & -0.161147 & 0.010774 & -14.95740 & 0.0000 \\
ZSAVINGS & 0.056040 & 0.010509 & 5.332660 & 0.0000 \\
ZAVGRATING & 0.036751 & 0.012476 & 2.945775 & 0.0033 \\
ZHVPP & 0.050264 & 0.010531 & 4.772852 & 0.0000 \\
ZHELPFULNUM & 0.050204 & 0.011945 & 4.202942 & 0.0000 \\
ZBALANCE & 0.042614 & 0.013040 & 3.267829 & 0.0011 \\
ZHNUM & 0.116387 & 0.017562 & 6.627105 & 0.0000 \\
ZHAVGIR & 0.052305 & 0.018761 & 2.787976 & 0.0054 \\
HRNSEQ & -0.088117 & 0.023689 & -3.719805 & 0.0002 \\
HIRSEQ & -0.092000 & 0.022983 & -4.002947 & 0.0001 \\
\hline \hline & & & & -2.266315 \\
R-squared & 0.356803 & Mean dependent var & & 0.487747 \\
Adjusted R-squared & 0.352260 & S.D. dependent var & & 0.975259 \\
S.E. of regression & 0.392550 & Akaike info criterion & 1.016608 \\
Sum squared resid & 261.8082 & Schwarz criterion & 0.990561 \\
Log likelihood & -821.8213 & Hannan-Quinn criter. & 0.417282 \\
F-statistic & 78.54113 & Durbin-Watson stat & \\
Prob(F-statistic) & 0.000000 & & & \\
\hline \hline
\end{tabular}

Dependent Variable: SALE

Method: Least Squares

Date: 04/17/18 Time: 16:56

Sample: 11713

Included observations: 1712

Huber-White-Hinkley (HC1) heteroskedasticity consistent standard errors and covariance

\begin{tabular}{crcrr}
\hline \hline Variable & Coefficient & Std. Error & t-Statistic & Prob. \\
\hline C & -2.128304 & 0.025471 & -83.55774 & 0.0000 \\
ZSALEPRICE & -0.140920 & 0.010455 & -13.47883 & 0.0000 \\
ZNOOFREVIEWS & 0.190332 & 0.015002 & 12.68697 & 0.0000 \\
ZAGE_WEEK & -0.161147 & 0.011583 & -13.91187 & 0.0000 \\
ZSAVINGS & 0.056040 & 0.010562 & 5.305638 & 0.0000 \\
ZAVGRATING & 0.036751 & 0.011293 & 3.254261 & 0.0012 \\
ZHVPP & 0.050264 & 0.010695 & 4.699763 & 0.0000 \\
ZHELPFULNUM & 0.050204 & 0.010721 & 4.683008 & 0.0000 \\
ZBALANCE & 0.042614 & 0.012908 & 3.301433 & 0.0010 \\
ZHNUM & 0.116387 & 0.019695 & 5.909603 & 0.0000 \\
ZHAVGIR & 0.052305 & 0.020360 & 2.568988 & 0.0103 \\
HRNSEQ & -0.088117 & 0.022514 & -3.913825 & 0.0001 \\
HIRSEQ & -0.092000 & 0.021444 & -4.290330 & 0.0000 \\
\hline \hline R-squared & 0.356803 & Mean dependent var & & -2.266315 \\
Adjusted R-squared & 0.352260 & S.D. dependent var & & 0.487747 \\
S.E. of regression & 0.392550 & Akaike info criterion & 0.975259 \\
Sum squared resid & 261.8082 & Schwarz criterion & & 1.016608 \\
Log likelihood & -821.8213 & Hannan-Quinn criter & 0.990561 \\
F-statistic & 78.54113 & Durbin-Watson stat & 0.417282 \\
& & & \\
\hline
\end{tabular}


Prob(F-statistic)

0.000000 Wald F-statistic

71.02313

Prob(Wald F-statistic)

0.000000

B.3 Test results of causality test between number of reviews and Salerank

Pairwise Granger Causality Tests

Date: 04/18/18 Time: 16:05

Sample: 11713

Lags: 2

\begin{tabular}{lccc}
\hline \hline Null Hypothesis: & Obs & F-Statistic & Prob. \\
\hline \hline NOOFREVIEWS does not Granger Cause SALERANK & \multirow{2}{*}{1708} & 5.68493 & 0.0035 \\
SALERANK does not Granger Cause NOOFREVIEWS & & 0.79268 & 0.4528 \\
\hline \hline
\end{tabular}

